\title{
Spatiotemporal Patterns and Social Risk Factors of Meningitis in Nigeria
}

\author{
Auwal F. Abdussalam ${ }^{*}$, Yasser Qaffas ${ }^{2}$ \\ ${ }^{1}$ Department of Geography, Faculty of Science, Kaduna State University, Kaduna, Nigeria \\ ${ }^{2}$ Urban and Regional Planning at the Faculty of Environmental Design, King Abdulaziz University, Jeddah, \\ Kingdom of Saudi Arabia \\ Email: *abdussalamauwal@gmail.com
}

Received 17 July 2016; accepted 27 August 2016; published 30 August 2016

Copyright (C) 2016 by authors and OALib.

This work is licensed under the Creative Commons Attribution International License (CC BY).

http://creativecommons.org/licenses/by/4.0/

(c) $\underset{\mathrm{EY}}{\mathrm{C}}$ Open Access

\begin{abstract}
This study aimed at characterising the spatiotemporal pattern of meningitis in Nigeria, in order to detect vulnerable areas. Stratified sampling was deployed in research inquiry based on the following variables: geographic location; population density; poverty status; and adult literacy level in accordance to diseases incidence rate. Population-based ratios were then computed for each stratum for the identification of high risk areas. Global Moran's Index spatial autocorrelation technique was additionally used to investigate the extent to which neighbouring values of incidence rate are correlated and to determine meningitis demographic risk factors. A significant spatial clustering of meningitis incidence rate has been found in northern Nigeria, with less or no clustering in the southern part of the country. A significant correlation of disease, with geographical location and poverty was perceived. The study commends that improving the socioeconomic status of the affected population may reduce the incidents of meningitis in the high risk area in Nigeria.
\end{abstract}

\section{Keywords}

Health Geography, Nigeria, Meningitis, Spatial Autocorrelation

Subject Areas: Environmental Sciences, Human Geography, Psychology, Statistics

\section{Introduction}

The outbreaks and epidemics of meningitis are occurring throughout the world, but are most severe in African countries, especially in the so called meningitis belt where parts of Nigeria lie. For several decades, this climate-sensitive disease has remained a major health and social problem in Nigeria, and continues to afflict the

*Corresponding author. 
nation both in epidemic magnitude and small outbreaks. According to World Health Organisation (WHO) records between 1991 and 2011, Nigeria alone reported over 393,614 (22,664) cases and deaths respectively. The first documented cases of meningitis were reported from the north eastern state of Bauchi in 1905. During the 1996 epidemic, for example, Nigeria alone reported over 100,000 cases and 11,000 deaths to the WHO [1], which were almost half of the total cases reported from the 25 countries within the belt. As in the case of other countries in West Africa, the human pathogen bacteria Neisseria meningitidis A [2], is responsible for most of the meningitis epidemics and outbreaks in Nigeria.

The disease has notable seasonality [3] and varies both spatially and temporally across the country, and is well documented to have been influenced by climatic, environmental, and social factors [4]-[6]. The disease primarily affects the country during the dry months, beginning with the Harmattan in November and continuing through May with peak incidence during the hottest months of March and April. Anecdotal evidence suggests that many people in northern Nigeria believe that the disease is caused by the intense heat usually experienced during disease outbreaks. In Nigeria, meningitis transmission may be influenced by many factors apart from climate, such as socioeconomic and cultural practices. In the cities, areas mostly occupied by low-income earners are densely populated with many people per household, and most use wood as their source of cooking fuel. Based on previous studies such as, e.g., [7], people living in these areas are likely to be at higher risk and more vulnerable to the development, carriage and transmission of invasive meningitis.

For the past years, meningitis in Africa and Nigeria in particular [4] has mainly caused by serogroup A [8]. The introduction of the polysaccharide protein conjugate A vaccine [9] brings hope for controlling the disease. The new vaccine will not only provide longer protection, but will also prevent the disease [10]; i.e. a whole population can be vaccinated proactively before meningitis epidemics are detected. Another advantage of the conjugate vaccine is carriage prevention [11]. Despite these advantages, since the conjugate vaccine is serogroup A specific [8] other serogroups like W135 [12] and C [13] might continue to circulate, increasing the risk of epidemics [14].

The recent outbreak of the disease confirms the above fear. According to the WHO (WHO, 2015), the epidemic in Niger and neighbouring Nigeria is being caused by different strain of the deadly bacterium, in fact, two strains-meningococcus $C$ and to a lesser extent, meningococcus W135. As at the $15^{\text {th }}$ of May, 2015 Niger has recorded over 5855 and 400 deaths, while in Nigeria the case tally stands at 1380 cases, including 83 deaths as of 5 April 2015, according to the Nigeria Centre for Disease Control (NCDC) of the Federal Ministry of Health $(\mathrm{FMoH})$. This is the first time that epidemics of meningitis W135 and C have occurred on this scale in Niger. An additional concern about the outbreak is the fact that it is being seen in densely populated urban areas. The outbreak that started in the cities of Niamey and Dosso, has now spread to ten districts from the regions of Niamey. Because of the large population centres and overcrowding, there is fear of high risk of rapid spread and a large caseload. The disease has been earlier associated with overcrowding e.g., [15].

Analysing long term surveillance epidemiological data is important for understanding the nature of the spatial and temporal dynamics of infectious diseases; this is in order to improve the methods and strategies of controlling them. It will also allow for the identification of high risk areas which would help greatly in investigating the driving factors responsible for the disease outbreaks, through understanding the characteristics of the risk area. The current study will investigate the spatial and time characteristics of meningitis, and identify the states and regions with high burden and risk; this would be achieved through exploring existing epidemiological records of the diseases using various statistical techniques.

This paper is the first to report on the spatial and temporal patterns of meningitis highlighted the social risks factors of the disease in Nigeria—where reported cases are always high.

\section{Materials and Methods}

\subsection{Epidemiological Data}

Three types of epidemiological data were obtained from different sources and at different spatial and temporal resolutions. Firstly, records of annual suspected meningitis cases and deaths at state levels between 2000 and 2011 were obtained from the epidemiology unit of the NCDC of the Nigerian FMoH. These cases are reported by DSNOs in all the 774 Local Government Areas (LGAs) of Nigeria. Secondly, annual national level records of reported cases and deaths from 1991 to 2011 were extracted from the archives of the WHO. Finally, a higher resolution data of weekly records of reported meningitis cases from the 774 districts in Nigeria between 2007 
and 2011 were obtained from WHO.

Cases definitions:

In Nigeria, meningitis case is defined according to the WHO case definition, and since all the cases in this study are suspected cases, is thus defined as follows:

A suspected meningitis case is defined: "as a person with sudden onset of fever $\left(>38.5^{\circ} \mathrm{C}\right.$ rectal or $38.0^{\circ} \mathrm{C}$ axillary) with one or more of following symptoms: neck stiffness, meningeal sign, or altered consciousness" [16].

\subsection{Socioeconomic and Population Data}

Annual socioeconomic data between 2000 and 2011 for the 36 states and Federal Capital Territory (FCT) in the country were obtained from the Nigerian National Bureau of Statistics (NBS). Data obtained includes percentages of population living in absolute poverty and adult literacy. State's population census (2006) was obtained from the Nigerian Population Commission (NPC), Nigeria. Annual population estimate for each state was calculated forward and backward using Nigerian population growth rate index provided by World Bank. Population density for each state was computed by dividing each state's population with its aerial cover in square kilometres.

\subsection{Measuring the Spatial and Time Distribution of Diseases}

Annual incidence rate (IR) per 100,000 of population and case fatality rate (CFR) for meningitis were computed from the WHO national records between 1991 and 2011. IR and CFR were also calculated for each of the 36 states in Nigeria and the Federal Capital Territory (FCT) Abuja, using the annual state levels cases and deaths reported between 2000 and 2011 obtained from NCDC.

The IR and CFR for both diseases at the states level for the 12 years of data (2000-2011) were classified into strata based on their respective values. ArcGIS was used to determine the cut-off point of each interval using the Jenks Natural Break method and subsequently mapped using different colours to represent each of the four intervals. This method basically classifies data by minimising and maximising the variance within and between classes respectively. Global Moran's Index spatial autocorrelation technique is used to investigate the extent to which neighbouring values of IR are correlated and to determine meningitis demographic risk factors. The spatial weighing function was determined in respect to the length of the common boundaries by assuming that the states that are sharing longer boundaries are more interconnected than states sharing shorter one or no boundary at all (e.g., [17]).

The states where classified into strata based on the following variables: geographic location; population density; poverty status; and adult literacy level according to diseases IR (Figures 1(a)-(d)). Population-based ratios were then computed for each stratum for the identification of high risk areas, using the stratum with the lowest value of IR in each of the four variables as reference point. To determine the association between these variables and diseases' IR, Mantel-Haenszel Chi Square test was used.

1) Geographic regions

Nigeria is divided into six geopolitical regions namely: northwest, northeast, northcentral, southwest, southsouth, and southeast (Figure 1(a)) consisting of 7, 6, 7, 6, 6, and 5 states respectively. For the purpose of identifying regions with the high burden and risk of the selected diseases, this official regional classification is adopted.

2) Population density

Population density for each of the 36 states and FCT per square kilometre was computed based on projected 2006 population census. Three strata namely: high, medium, and low densely populated were identified, with each consisting of 11, 11, and 15 states (Figure $1(\mathbf{b})$ ).

3) Poverty status

Four poverty strata were identified based on the mean of the percentage of population living in absolute poverty per state between 2000 and 2011. In Nigeria, absolute poverty is defined as the percentage of population with income less than a fixed proportion of median income. Classification was made based on states with very-high, high, medium, and low poverty, with each of the stratum consisting of $11,11,10$, and 5 states respectively (Figure 1(c)).

4) Adult literacy 
(a) Regions

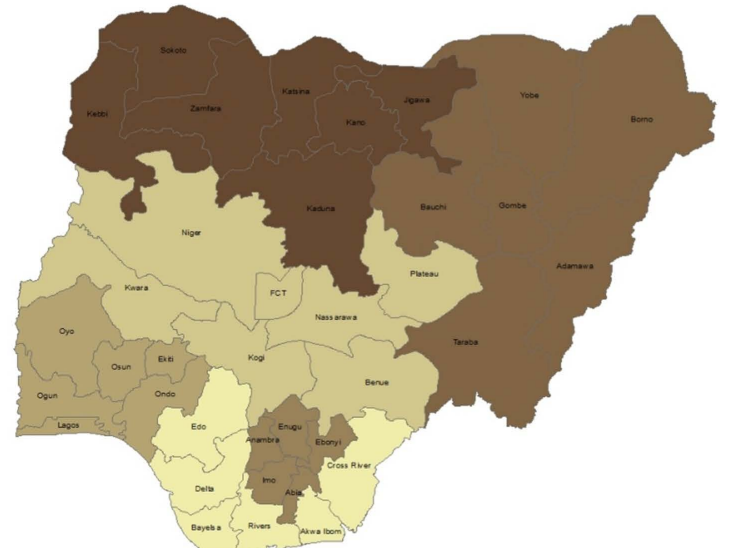

\begin{tabular}{|c|c|}
\hline \multirow{2}{*}{$\begin{array}{l}\text { LEGEND } \\
\text { Geopolitical Regions }\end{array}$} & \\
\hline & \\
\hline \begin{tabular}{l|l} 
& Southsouth \\
\end{tabular} & Southwest \\
\hline Northcentral & Northeast \\
\hline Southeast & Northwest \\
\hline
\end{tabular}

(c) Absolute Poverty

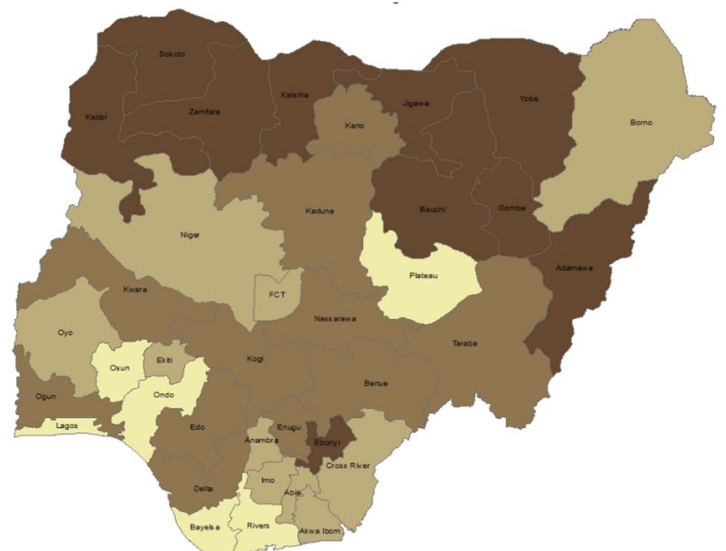

\begin{tabular}{|l|l|}
\hline \multicolumn{2}{|l|}{ LEGEND } \\
\hline \multicolumn{2}{|c|}{ Absolute poverty (\%) } \\
\hline & $0.37-0.48$ \\
\hline & $0.49-0.57$ \\
\hline & $0.58-0.68$ \\
\hline & $0.69-0.81$ \\
\hline
\end{tabular} (b) Population density

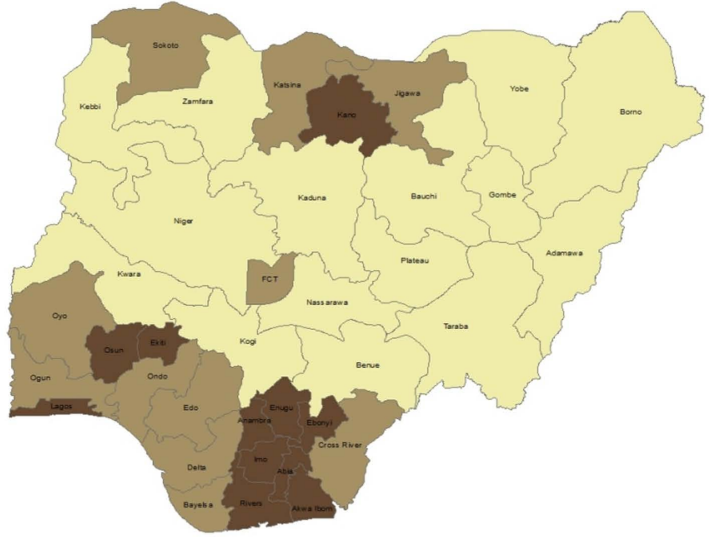

\begin{tabular}{|l|l|}
\hline \multicolumn{2}{|l|}{ LEGEND } \\
\hline Population Density $(\mathrm{SqKm})$ \\
\hline $50-149$ \\
\hline $150-299$ \\
\hline $300-3000$ \\
\hline
\end{tabular}

(d) Adult Literacy

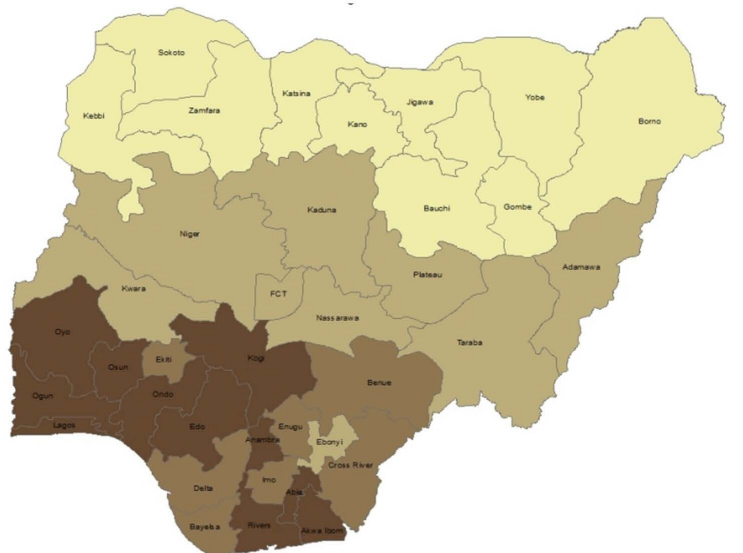

Figure 1. Map of Nigeria showing: (a) Six geopolitical regions (Northwest, Northeast, Southwest, Southeast, Northcentral, and Southsouth) grouped based on the official classification of Nigeria regions, (b) Three population density strata, grouped based on projected 2006 population census computed using individual state sizes in Square kilometre, (c) Four poverty strata, grouped based on mean percentage of population living in absolute poverty per state between 2000 and 2011. Absolute poverty here is defined as the percentage of population that have income less than the median income, and (d) Four literacy strata, grouped based on mean percentage of population with adult literacy per state between 2000 and 2011. Adult literacy is measured on the ability to read and write with understanding, in English or in any of the Nigerian native languages. Adapted from [31].

States were stratified into four, based on mean percentage of population with adult literacy per state between 2000 and 2011. In Nigeria, adult literacy is measured on the ability to read and write with understanding, in English or in any of the Nigerian native languages. Classification was made as states with very-high, high, medium, and low literate adults, with each of the stratum consisting of 10, 7, 8, and 10 states respectively (Figure 
$1(d))$.

In order to investigate the time coherence (interannual variability) of the disease within states in Nigeria, the state level annual cases between 2000 and 2011 were standardised for each state. An average standardised time series from the most affected states were generated and correlated with individual states. Furthermore, the temporal and spatial distribution of a higher resolution meningitis cases was studied using the cumulative weekly district level cases districts between 2007 and 2012.

\section{Results}

The cumulated number of meningitis cases and deaths between 1991 and 2011 according to the WHO record is 380,699 and 28,898 respectively, with a cumulative IR (240.3) and CFR (7.6\%). Table 1 shows that within this 22-year period, $62 \%$ and $65 \%$ of the total cases and deaths occurred in the epidemics years of 1996, 2003, 2006, and 2009. The highest number of cases $(108,568 \mathrm{IR}=98.9)$ and deaths $(11,231 \mathrm{CFR}=10.3 \%)$ occurred in the epidemic years of 1996, while the lowest cases $(2466 \mathrm{IR}=1.6)$ and deaths $(141$, CFR $=5.7 \%)$ occurred in 2011. Figure 2 allows for the visualisation of the disease variability between 1991 and 2011 which is characterised with three conspicuous peaks (1996, 2003, and 2006) that occurred at the intervals of eight and six years respectively.

The annual state level data allows for investigating the spatial distribution of meningitis across the country. Within the 12 years of data (2000-2011), over $98 \%$ and $94 \%$ of cases and deaths have occurred in the northern states. Specifically $78 \%$ and $77 \%$ of cases and deaths respectively that occurred within this period were reported from the northern states of Kano, Kaduna, Katsina, Kebbi, Sokoto, Zamfara, Jigawa, and Bauchi. This is suggesting that most of the cases and deaths have occurred in states from the northwest region of the country. By

Table 1. Suspected meningitis cases and deaths, incidence rate per 100,000 of population, and case fatality rates for Nigeria between 1991 and 2011.

\begin{tabular}{|c|c|c|c|c|}
\hline Year & Cases & Deaths & IR & CFR\% \\
\hline 1991 & 6992 & 695 & 7.2 & 9.9 \\
\hline 1992 & 6418 & 563 & 6.4 & 8.8 \\
\hline 1993 & 4209 & 472 & 4.2 & 11.2 \\
\hline 1994 & 6014 & 437 & 5.7 & 7.3 \\
\hline 1995 & 7376 & 1388 & 6.9 & 18.8 \\
\hline 1996 & 108,568 & 11231 & 98.9 & 10.3 \\
\hline 1997 & 39,973 & 965 & 35.5 & 2.4 \\
\hline 1998 & 10,793 & 797 & 9.4 & 7.4 \\
\hline 1999 & 4599 & 222 & 3.9 & 4.8 \\
\hline 2000 & 5783 & 509 & 4.8 & 8.8 \\
\hline 2001 & 7656 & 691 & 6.2 & 9.0 \\
\hline 2002 & 6544 & 655 & 5.2 & 10.0 \\
\hline 2003 & 35,663 & 4142 & 27.5 & 11.6 \\
\hline 2004 & 9489 & 650 & 7.2 & 6.9 \\
\hline 2005 & 4988 & 362 & 3.7 & 7.3 \\
\hline 2006 & 13,075 & 492 & 9.4 & 3.8 \\
\hline 2007 & 5509 & 444 & 3.8 & 8.1 \\
\hline 2008 & 8981 & 625 & 6.1 & 7.0 \\
\hline 2009 & 79,335 & 2916 & 52.6 & 3.7 \\
\hline 2010 & 6268 & 501 & 4.1 & 8.0 \\
\hline 2011 & 2466 & 141 & 1.6 & 5.7 \\
\hline
\end{tabular}




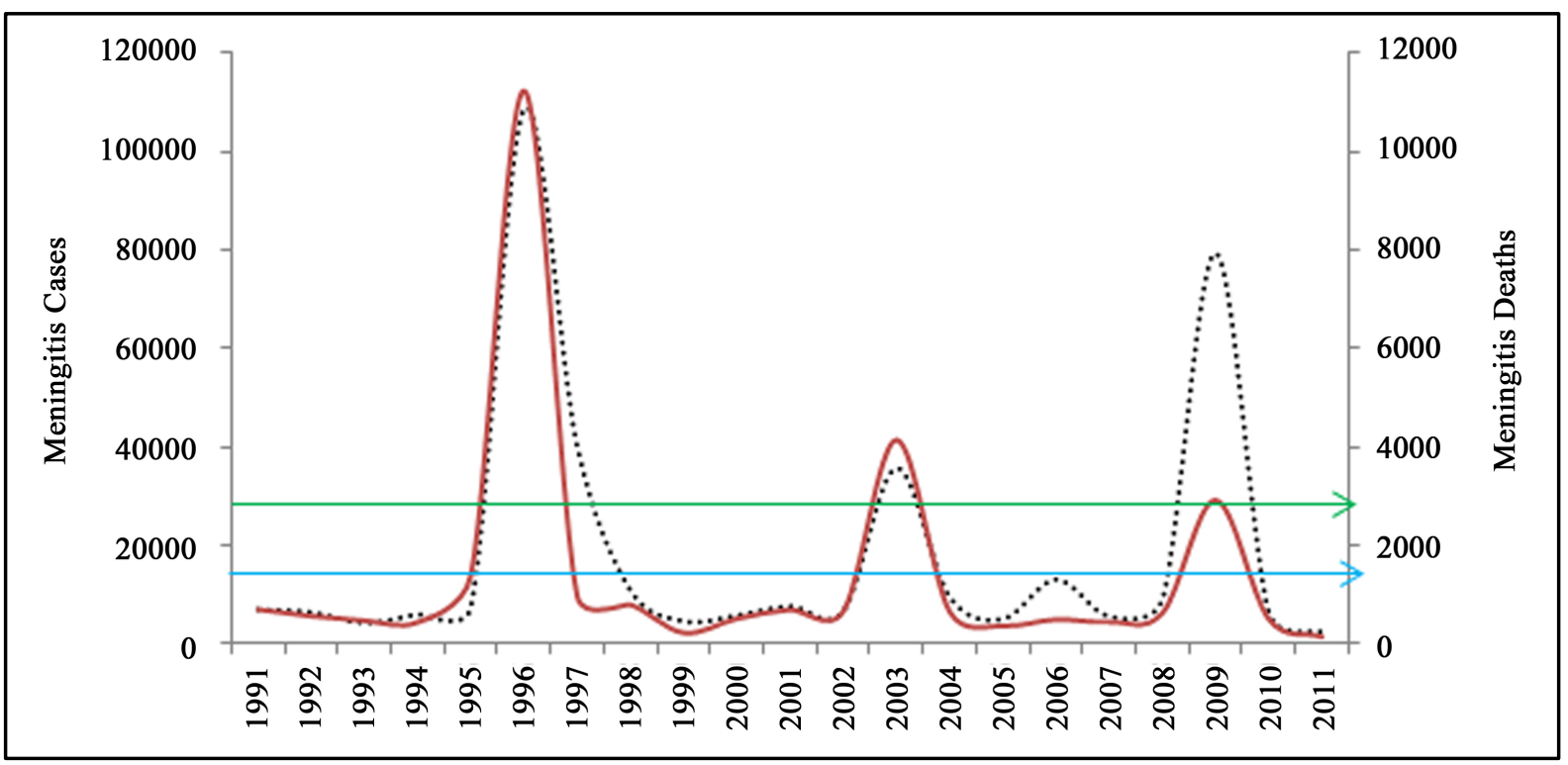

Figure 2. Annual meningitis suspected cases (dashed-black) and deaths (red) between 1991 and 2011 in Nigeria. The blue and green arrows indicate the average and standard deviation of cases respectively.

looking at cases occurring with respect to the population, the most affected states with the highest cumulative IR are; Kebbi (72.3), Jigawa (48.6), Kano (46.2), and Sokoto (41.7), while the least affected states comes from the southern part of the country. For example, states such as Akwa Ibom, and Imo have IR of less than 0.04 with no reported death.

Spatial autocorrelation was computed in order to measure the extent of neighbourhood between IR values using the Global Moran's Index. A statistically significant positive spatial autocorrelation for cumulative IR of meningitis from 2000-2011 (Moran's I $=0.235, \mathrm{z}=2.69, \mathrm{p}=0007$ ) is analysed. Furthermore, spatial autocorrelation was computed for each year and were all found to be statistically significant ( $p=0.000-0.025$ ) (Table 2).

Statistically significant clusters were detected in the cumulative IR between 2000 and 2011, reflecting a northsouth steep spatial gradient with clustering of highest IR in the northern states of the country (Figure 3). The clustering of high rates of meningitis at the northwest and northeast was persistent in these regions in all the years (2000-2011) shown in Figure 3. Tables 2(a)-(d) show the rate-ratios computed within each stratum, IR was remarkably higher in the northwest (81.5 times), northeast (33.2 times), and northcentral (5.2 times) regions if compared with the lowest stratum-the southeast region. Chi Square reveals a statistically significant positive relationship with poverty $(\mathrm{p} \leq 0.04)$, while a positive but not statically significant relationship was observed with population density ( $\mathrm{p} \geq 0.05$ ). In the case of adult literacy, an inverse but significant relationship was seen ( $\mathrm{p}$ 0.05). Tables 2(a)-(d) show that the IR of the poorest and densely populated strata are 34.8 and 2.1 times higher than that of their respective lowest stratum, while in the adult literacy stratum IR is 41.6 times higher in population with less educated literates if compared with that of the highly educated ones.

Meningitis is not evenly distributed across the country; Table 3 shows incidence rate being much higher in the northern states of the country most especially the northwest (336 per 100,000) and northeast (149 per $100,000)$ regions, followed by the central region (28 per 100,000). The southern states are having the least of IR ranging between 0.1 and 0.9 per 100,000. This steep latitudinal gradient is shown in Figure 3.

Mapping the district levels suspected meningitis cases between 2007 and 2012 allows for the visualisation of the spatial distribution of the disease outbreak (Figure 4). In all the seven years of data, disease cases show a consistent clustering in the northwest region of the country. Although cases have been reported from the southern districts periodically, but are recently more occurring in this part of the country, example is in year 2010 and 2011. The temporal distribution of meningitis on weekly resolution is shown in Figure 5 for the 6 years of available data (2007-2012). In all the years shown, the season has been consistently starting between week 43 and 46, peaking between week 12 and 16 and then began to subside between week 20 and 22 . The disease season onset is corresponding with onset of the Harmattan and continues throughout the dry season, and then subsides with the appreciation of humidity and the onset of the rainy season. Cases were observed to have begun 
Table 2. Global Moran's Index spatial autocorrelation computed for cumulative meningitis incidence rate (2000-2011), and for each year between this period using state level data.

\begin{tabular}{ccc}
\hline Year & Moran's Index & -Value \\
2000 & 0.113 & 0.013 \\
2001 & 0.023 & 0.003 \\
2002 & 0.173 & 0.016 \\
2003 & 0.231 & 0.005 \\
2004 & 0.302 & 0.025 \\
2005 & 0.122 & 0.001 \\
2006 & 0.271 & 0.001 \\
2007 & 0.136 & 0.004 \\
2008 & 0.217 & 0.001 \\
2009 & 0.191 & 0.003 \\
2010 & 0.318 & 0.000 \\
2011 & 0.201 & 0.002 \\
\hline
\end{tabular}

Table 3. Meningitis incidence rate and population-based rate ratio by strata of states classified based on (a) geopolitical locations, (b) population density, (c) percentage of population living in absolute poverty, and (d) percentage of literate adults between 2000 and 2011.

\begin{tabular}{|c|c|c|c|c|}
\hline \multicolumn{5}{|c|}{ (a) } \\
\hline Geopolitical region & Meningitis cases & Population & IR (per 100,000) & Rate ratio \\
\hline Northwest & 144,086 & $40,497,542$ & 355.8 & 81.5 \\
\hline Northeast & 31,088 & $21,469,225$ & 144.8 & 33.2 \\
\hline Northcentral & 5210 & $22,933,883$ & 22.7 & 5.2 \\
\hline Southsouth & 3022 & $23,780,792$ & 12.7 & 2.9 \\
\hline Southeast & 989 & $18,538,039$ & 5.3 & 1.2 \\
\hline Southwest & 1362 & $31,212,581$ & 4.4 & Reference \\
\hline \multicolumn{5}{|c|}{ (b) } \\
\hline Population density & Meningitis cases & Population & IR (per 100,000) & Rate ratio \\
\hline High & 90,841 & $57,031,901$ & 159.2 & 2.1 \\
\hline Medium & 53,157 & $45,166,916$ & 117.7 & 1.6 \\
\hline Low & 41,759 & $56,233,246$ & 74.26 & Reference \\
\hline \multicolumn{5}{|c|}{ (c) } \\
\hline Absolute poverty \% & Meningitis cases & Population & IR (per 100,000) & Rate ratio \\
\hline Low & 2278 & $29,360,751$ & 7.8 & Reference \\
\hline Medium & 7905 & $39,881,488$ & 19.8 & 2.6 \\
\hline High & 68,642 & $495,485,94$ & 138.5 & 17.9 \\
\hline Very high & 106,932 & $39,641,231$ & 269.7 & 34.8 \\
\hline \multicolumn{5}{|c|}{ (d) } \\
\hline Adult literacy \% & Meningitis cases & Population & IR (per 100,000) & Rate ratio \\
\hline Low & 149,963 & $48,912,976$ & 306.6 & 41.6 \\
\hline Medium & 29,280 & $29,962,622$ & 97.7 & 13.3 \\
\hline High & 2530 & $25,446,225$ & 9.9 & 1.4 \\
\hline Very high & 3984 & $54,110,240$ & 7.4 & Reference \\
\hline
\end{tabular}


(a) Meningitis IR
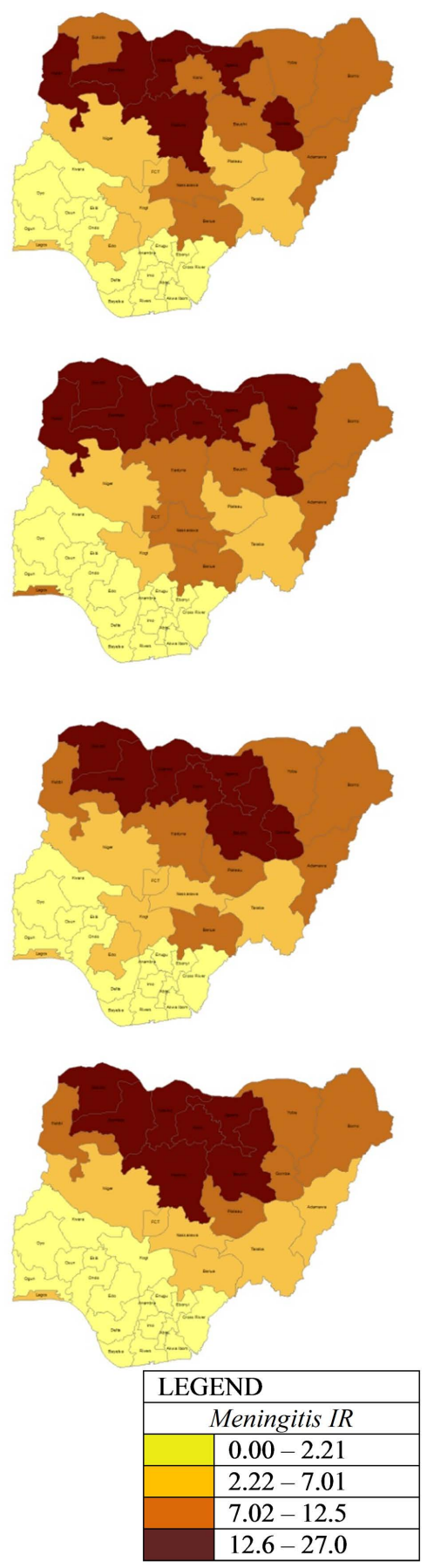

2003

(b) Meningitis CFR

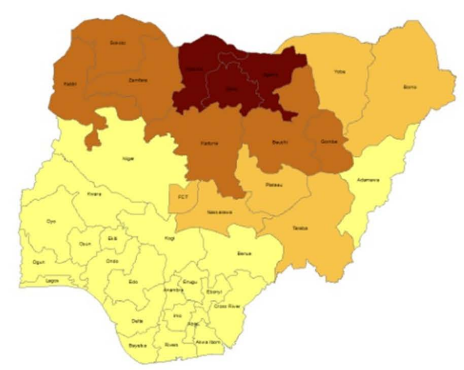

2006

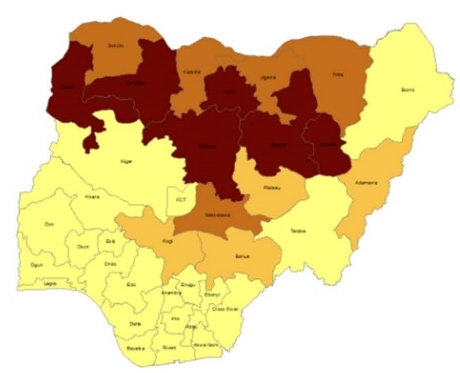

2009

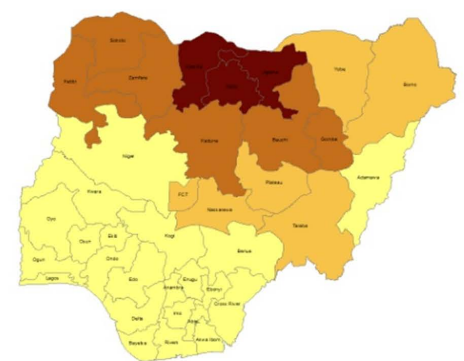

$2000-2011$

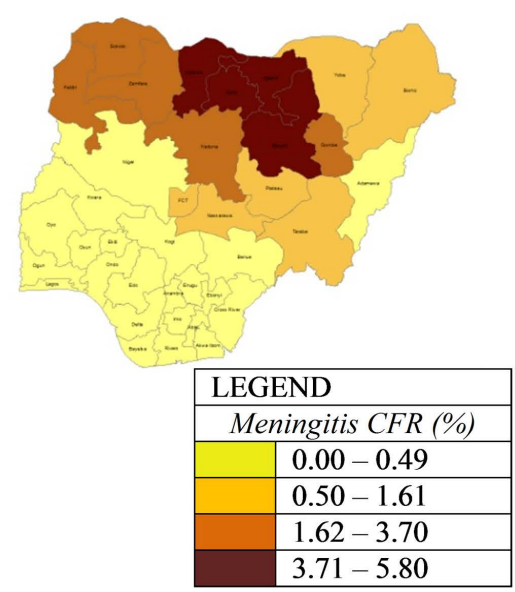

Figure 3. Spatial distribution of states level annual incidence rate per 100,000 for population (left) and case fatality rate (right) of meningitis for 2003, 2006, 2009 and the cumulative incidence rate between 2000 and 2011.

early in 1995 leading to one of the pronounced epidemic year in 1996. A fairly consistent interannual variability pattern was observed for meningitis in all the reporting districts between 2007 and 2012.

Correlating the standardised annual cases of meningitis from each state with an averaged time series from the most affected states allows for investigating whether there is time coherence in the interannual variability of the 
2007

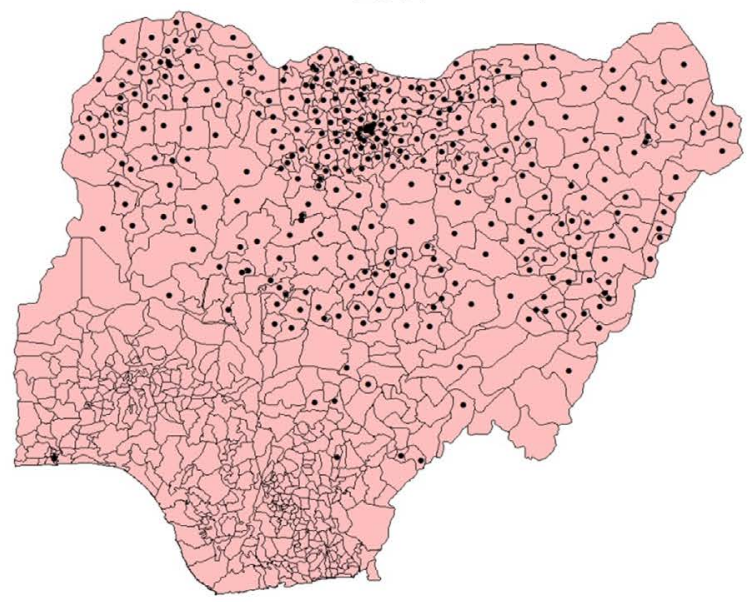

2009

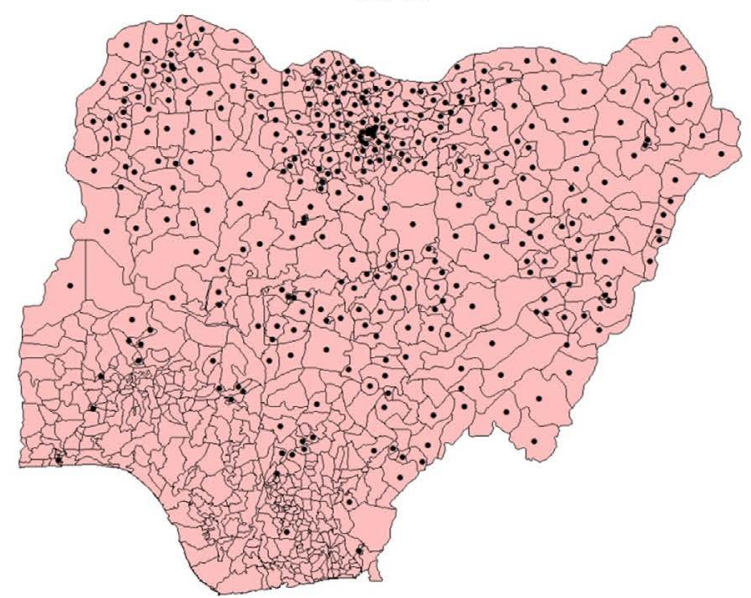

2011

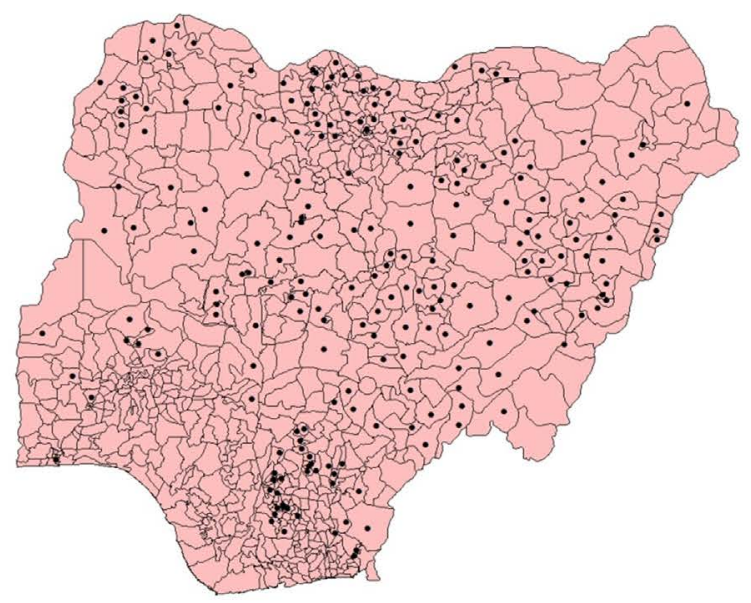

2008

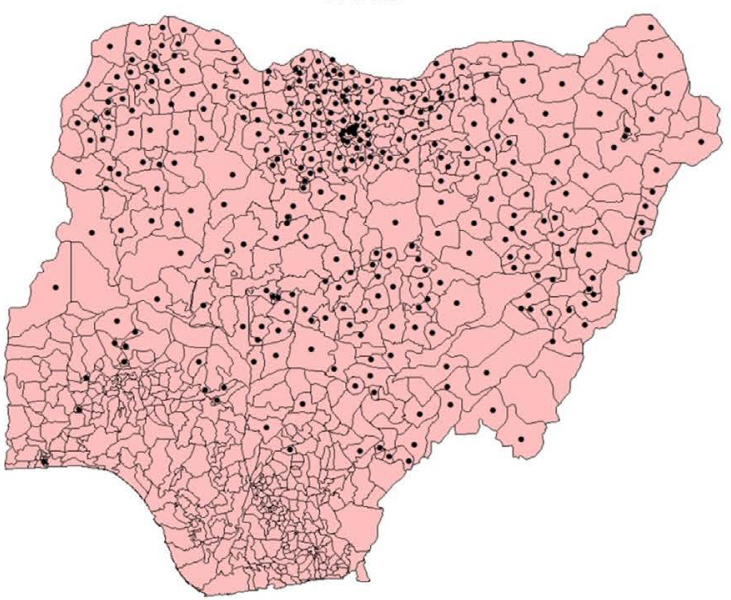

2010

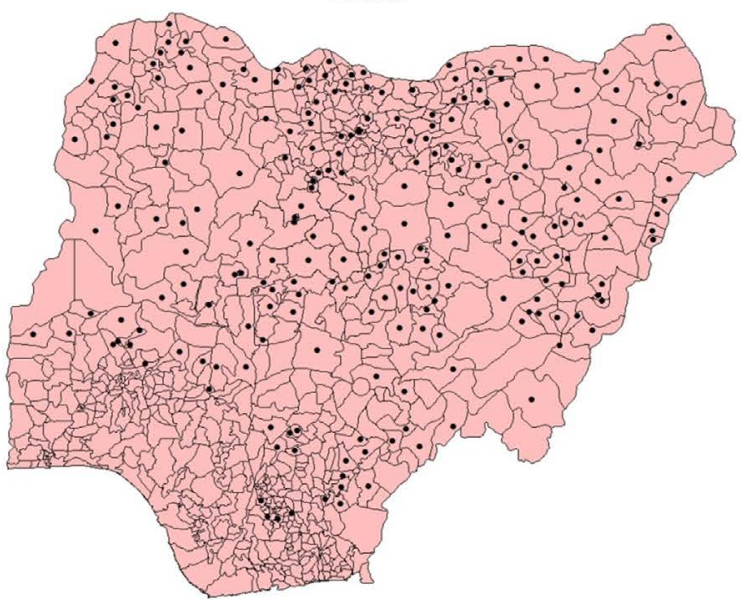

2012

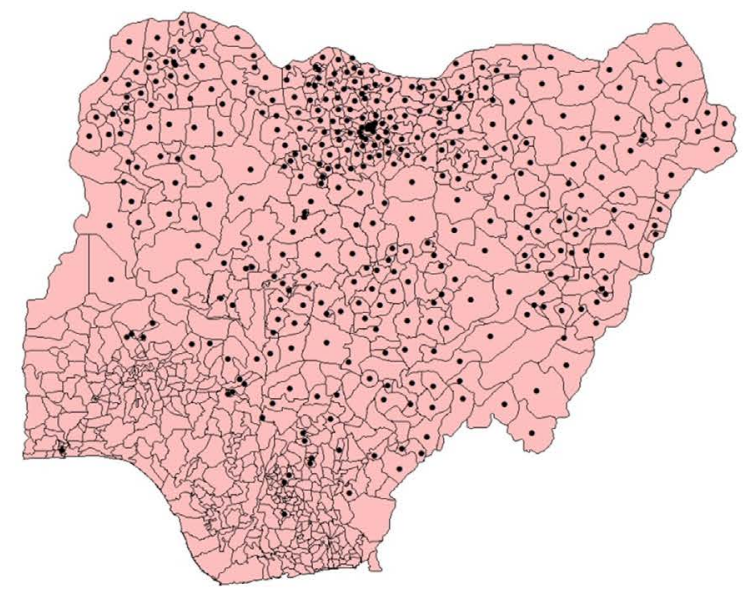

Figure 4. Spatial distribution of weekly reported cases of meningitis from 774 districts in Nigeria to WHO between 2007 and 2012. The black dot indicates if at least one case is reported from a particular district in the year.

disease occurrence within states. As expected, states from northern part of the country show higher correlations (0.61 - 0.92) with reference time series (Figure 6), followed by those from the southwest and northcentral $(0.29-0.60)$ with the exception Taraba state. The least correlated states are found in the south-south region of the country. 

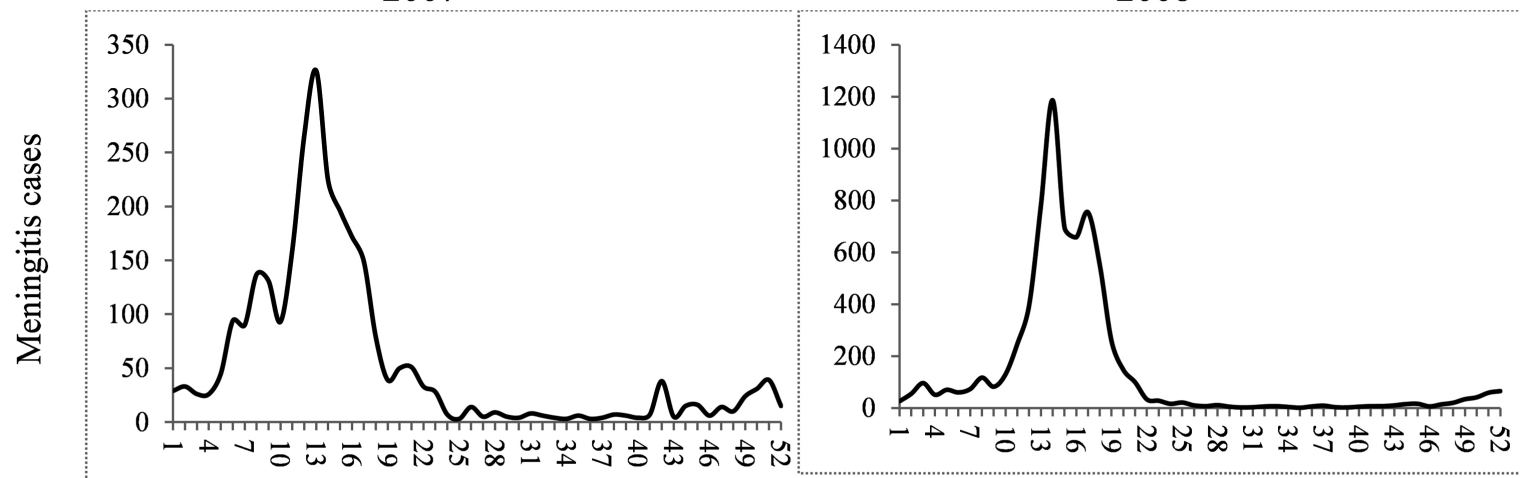

2009

2010

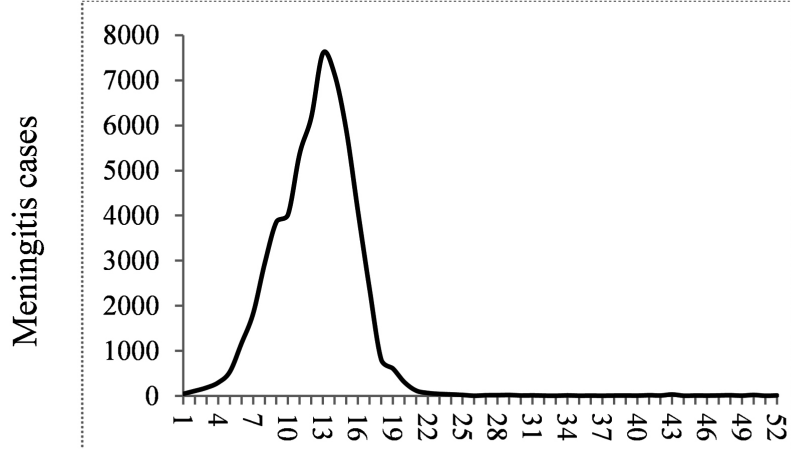

2011
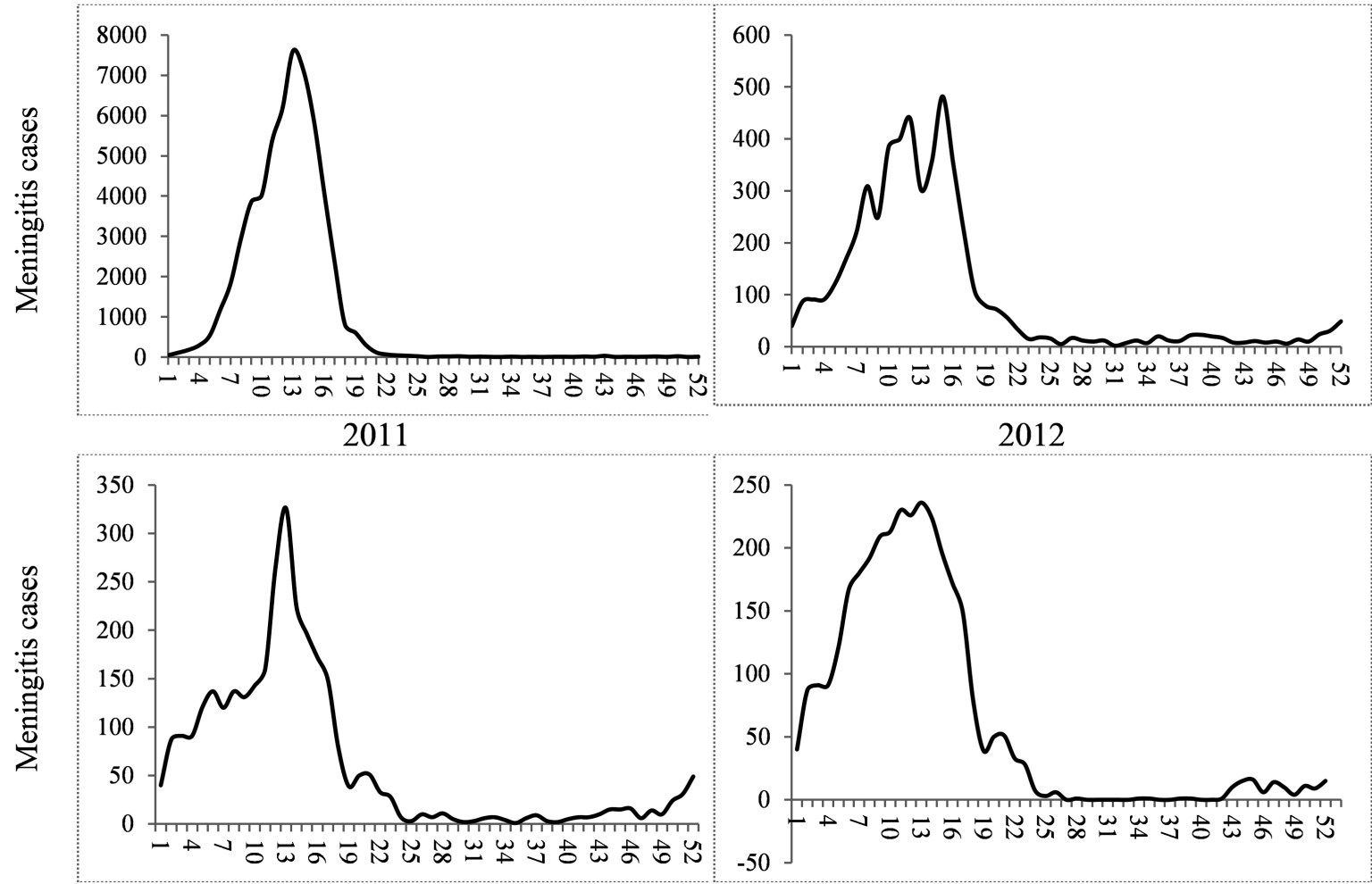

Week

2012

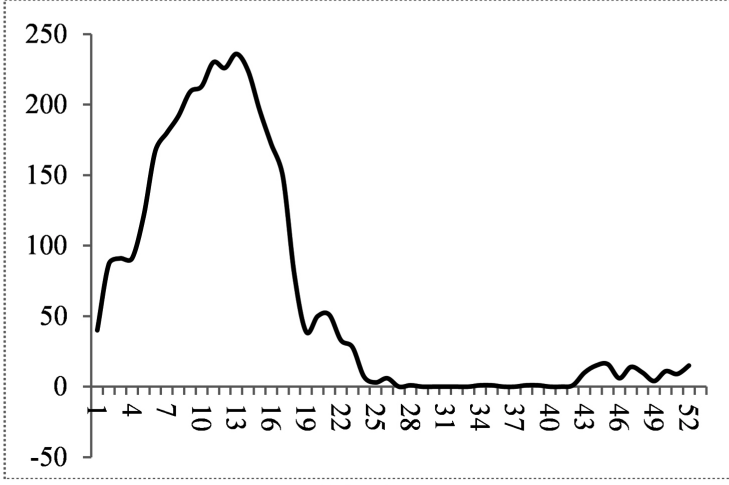

Week

Figure 5. Weekly cycles of districts level meningitis cases reported to WHO from Nigeria between 2007 and 2012.

\section{Discussions}

For decades, meningitis has remained important public health and social problems in Nigeria. This disease has become endemic in the poorest and less educated states of northern Nigeria; notably Borno, Kano, Katsina, Sokoto, Yobe and Adamawa. Lower IR and CFR were seen in the southern part of country. Analysing the spatial autocorrelation for individual years of state level data (Table 2) showed that irrespective of epidemic or nonepidemic year, there is persistent significant positive clustering $(\mathrm{p}<0.05)$ of cases in the northern part of the country. Also time coherence in terms of the interannual variability of disease occurrences is seen most especially in the northern part of the country.

Higher incidence of meningitis in the northern regions may have been influenced by climatic, environmental, and social conditions. Firstly, in terms of socioeconomic status, northern states such as Katsina, Kebbi, Sokoto, Zamfara, Jigawa, and Bauchi are among the poorest and less educated states (Figure 1). Secondly, meningitis incidence has been well documented to be influenced by hot, dry, and dusty weather conditions which the 


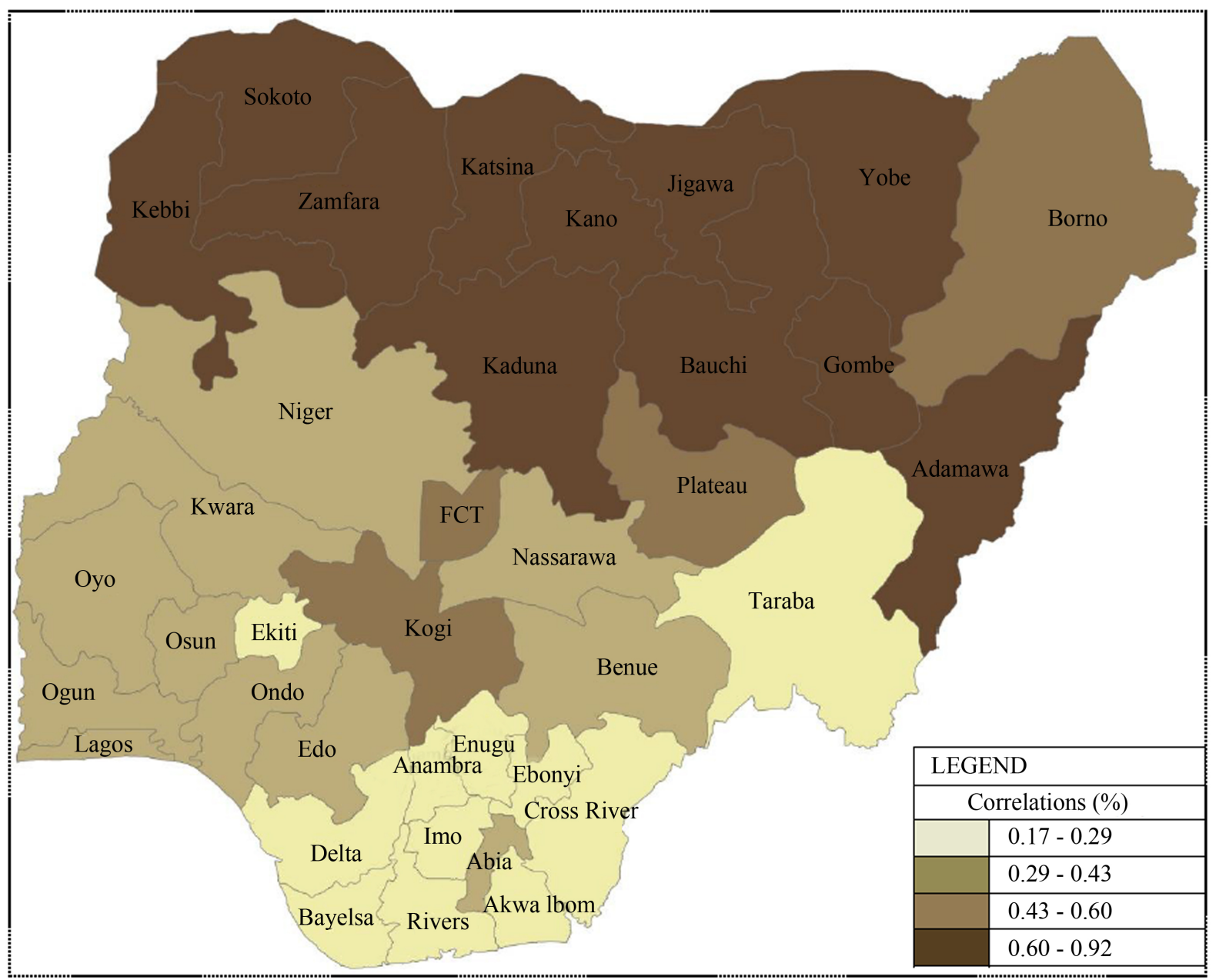

Figure 6. Time coherence of the interannual variability of standardised meningitis cases within states of Nigeria between 2000 and 2011.

northern region has favoured very well. Hypothetically, these might be the reasons why fewer cases are reported towards the coastal regions where humidity is always high round the year. Anecdotal evidence has shown that Harmattan do not usually propagate to the coast, however, recently people residing in this region of the country have been experiencing the encroachment of the dry and dusty wind. This change in weather condition might be responsible for the increasing cases being observed in this area, although are still small if compared with that of the northern regions.

Results from this study confirm that absolute poverty, adult literacy and population density are very important social factors in determining the spatial distribution of meningitis in addition to climate. For example, previous studies have linked the incidence of meningitis with upper respiratory tract infections (URTIs) such as pneumococcal pneumonia [18], exposure to smoke from cooking fires [7], overcrowding [15], disco patronage [19], and smoking [20]. In order to attain precision in simulating and possibly predicting any kind of climate-related disease epidemic, if possible, climatic variables should be jointly used with other non-climatic factors as explanatory variables [21] [22].

During the last decade, countries located south of the meningitis belt have been reported to have experienced large epidemics, these countries includes Togo, Cameroon, Cote d'Ivoire and Benin [23] [24]. Also some countries in East Africa such as Kenya, Uganda, and Tanzania have also suffered large epidemics [6] [25] [26], suggesting the southward spread of the so called meningitis belt which is believed to have begun since the great Sahelian drought in the late 1960s [27]. Despite this extension, these countries have a lower mean number of cases if compared with those in the belt [28]. There are also observed changes into the epidemiology of sero- 
group, after the introduction of the MenAfric vaccine in 2010 in some countries of the belt, $\mathrm{Nm}$ W135 was observed to be largely responsible for the outbreak of meningitis in Cote d'Ivore, Ghana, Benin and Burkina Faso [29].

The recent outbreak of the disease is being caused by different strain of the deadly bacterium, in fact, two strains-meningococcus C and to a lesser extent, meningococcus W135. As at the $15^{\text {th }}$ of May, 2015 Niger has recorded over 5855 and 400 deaths, while in Nigeria the case tally stands at 1380 cases, including 83 deaths as of 5 April 2015, according to the NCDC. This is the first time that epidemics of meningitis W135 and C have occurred on this scale in Niger. An additional concern about the outbreak is the fact that it is being seen in a densely populated urban area. The outbreak that started in the cities of Niamey and Dosso, has now spread to ten districts from the regions of Niamey. Because of the large population centres and overcrowding, there is fear of high risk of rapid spread and a large caseload. There is a need for the introduction of the quadrivalent meningococcal vaccine, which protects against $\mathrm{N}$. meningitidis serogroups $\mathrm{A}, \mathrm{C}, \mathrm{W}$, and $\mathrm{Y}$ in the belt. This is necessary because with the changing climate, there is the potentials risk of increasing cases due to warming climate [30].

In Nigeria, during the last decade, significant changes in the epidemiology of meningitis have been observed; cases of meningitis are now experienced in the southern part of the country, where the Harmattan is seldom experienced. Recent epidemiological data are showing increasing suspected cases of meningitis in the southern states of Nigeria. Figure 4 illustrates the spatial distribution of weekly districts levels meningitis cases reported between 2007 and 2012, as can be seen clearly, cases are reported from southern districts most especially in 2010 and 2012 disease years. Cases occurring in that part of the country might not be unconnected with the southward annual temporary relocation of people from the northern region of the country, or possibly due to the "Saheliazation" as observed in Ivory Coast [31].

The result of the spatial autocorrelation should be treated with caution; this is because in Nigeria, national surveillance data may have been marred with uncertainties because of underreporting of cases, particularly in remote villages where access to health care facilities is difficult or totally absent. Population living in these areas tend not to report cases by resorting to traditional medication, and when death occurred they hurriedly buried the body without reporting. Another issue is the differences in sizes and shapes among the states which may affect the scales of spatial patterns that could be detected. Also the relatively small number of states (only 36 states and FCT) may reduce the robustness of the spatial correlation.

\section{Conclusion}

The study has identified the hotspots of meningitis in the Nigeria, and confirms the important role of social risk factors on the spatial distribution of this infectious disease. Geographical location, poverty, overcrowding and literacy status all appear to be linked to the spatiotemporal distribution of diseases in addition to climate [32]. The results help in identifying specific regions where research should be focused; it will also help in knowing where attention should be given in terms of human and resource allocation by relevant authorities.

\section{References}

[1] Mohammed, I. and Nasidi, A. (2000) A Severe Epidemic of Meningococcal Meningitis in Nigeria. Transactions of the Royal Society of Tropical Medicine and Hygiene, 94, 265-270. http://dx.doi.org/10.1016/S0035-9203(00)90316-X

[2] WHO (2013) Climate Change and Health. http://www.who.int/mediacentre/factsheets/fs266/en/

[3] Pascual, M., Bouma, M.J. and Dobson, A.P. (2002) Cholera and Climate: Revisiting the Quantitative Evidence. Microbes and Infection, 4, 237-245. http://dx.doi.org/10.1016/S1286-4579(01)01533-7

[4] Abdussalam, A.F., et al. (2014) Climate Influences on Meningitis Incidence in Northwest Nigeria. Weather, Climate \& Society, 6. http://dx.doi.org/10.1175/WCAS-D-13-00004.1

[5] Dukic, V., et al. (2012) The Role of Weather in Meningitis Outbreaks in Navrongo, Ghana: A Generalized Additive Modeling Approach. Journal of Agricultural Biological and Environmental Statistics, 17, 442-460. http://dx.doi.org/10.1007/s13253-012-0095-9

[6] Greenwood, B. (2006) Editorial: 100 Years of Epidemic Meningitis in West Africa-Has Anything Changed? Tropical Medicine and International Health, 11, 773-780. http://dx.doi.org/10.1111/j.1365-3156.2006.01639.x

[7] Hodgson, A., et al. (2001) Risk Factors for Meningococcal Meningitis in Northern Ghana. Transactions of the Royal Society of Tropical Medicine and Hygiene, 95, 477-480. http://dx.doi.org/10.1016/S0035-9203(01)90007-0

[8] Greenwood, B. and Stuart, J.M. (2012) A Vaccine to Prevent Epidemic Meningitis in Africa. Lancet Infectious Dis- 
eases, 12, 738-739. http://dx.doi.org/10.1016/S1473-3099(12)70182-2

[9] Roberts, L. (2008) An Ill Wind, Bringing Meningitis. Science, 320, 1710-1715. http://dx.doi.org/10.1126/science.320.5884.1710

[10] WHO (2012) Meningococcal Meningitis. http://www.who.int/mediacentre/factsheets/fs141/en/

[11] Vestrheim, D.F., et al. (2010) Impact of a Pneumococcal Conjugate Vaccination Program on Carriage among Children in Norway. Clinical and Vaccine Immunology, 17, 325-334. http://dx.doi.org/10.1128/CVI.00435-09

[12] Decosas, J. and Koama, J.B.T. (2002) Chronicle of an Outbreak Foretold: Meningococcal Meningitis W135 in Burkina Faso. Lancet Infectious Diseases, 2, 763-765. http://dx.doi.org/10.1016/S1473-3099(02)00455-3

[13] Broome, C.V., et al. (1983) Epidemic Group-C Meningococcal Meningitis in Upper Volta, 1979. Bulletin of the World Health Organization, 61, 325-330.

[14] WHO (2015) Rapidly Growing Outbreak of Meningococcal Disease in Niger. http://www.who.int/mediacentre/news/situation-assessments/meningitis-niger/en/

[15] Brundage, J. and Zollinger, W. (1987) Evolution of Meningococcal Disease Epidemiology in the US Army. Evolution of Meningococcal Disease, 1, 5-25.

[16] WHO (2010) Managing Meningitis Epidemic in Africa: A Quick Reference Guide for Health Authorities and HealthCare Workers. WHO/HSE/GAR/ERI/2010.4, 23 p. http://whqlibdoc.who.int/hq/2010/WHO_HSE_GAR_ERI_2010.4_eng.pdf

[17] Borroto, R.J. and Martinez-Piedra, R. (2000) Geographical Patterns of Cholera in Mexico, 1991-1996. International Journal of Epidemiology, 29, 764-772. http://dx.doi.org/10.1093/ije/29.4.764

[18] Moore, P.S., et al. (1990) Respiratory Viruses and Mycoplasma as Cofactors for Epidemic Group-A Meningococcal Meningitis. JAMA, 264, 1271-1275. http://dx.doi.org/10.1001/jama.1990.03450100061026

[19] Cookson, S.T., et al. (1998) Disco Fever: Epidemic Meningococcal Disease in Northeastern Argentina Associated with Disco Patronage. Journal of Infectious Diseases, 178, 266-269. http://dx.doi.org/10.1086/517450

[20] Fischer, M., et al. (1997) Tobacco Smoke as a Risk Factor for Meningococcal Disease. Pediatric Infectious Disease Journal, 16, 979-983. http://dx.doi.org/10.1097/00006454-199710000-00015

[21] Thomson, M.C., et al. (2006) Potential of Environmental Models to Predict Meningitis Epidemics in Africa. Tropical Medicine \& International Health, 11, 781-788. http://dx.doi.org/10.1111/j.1365-3156.2006.01630.x

[22] Palmgren, H. (2009) Meningococcal Disease and Climate. Global Health Action, 2, 1-8. http://dx.doi.org/10.3402/gha.v2i0.2061

[23] Cunin, P., et al. (2003) Serogroup a Neisseria Meningitidis outside Meningitis Belt in Southwest Cameroon. Emerging Infectious Diseases, 9, 1351-1353. http://dx.doi.org/10.3201/eid0910.030170

[24] Halperin, S.A., et al. (2012) The Changing and Dynamic Epidemiology of Meningococcal Disease. Vaccine, 30, B26B36. http://dx.doi.org/10.1016/j.vaccine.2011.12.032

[25] Molesworth, A.M., et al. (2002) Where Is the Meningitis Belt? Defining an Area at Risk of Epidemic Meningitis in Africa. Transactions of the Royal Society of Tropical Medicine and Hygiene, 96, 242-249. http://dx.doi.org/10.1016/S0035-9203(02)90089-1

[26] Moore, P.S. (1992) Meningococcal Meningitis in Sub-Saharan Africa-A Model for the Epidemic Process. Clinical Infectious Diseases, 14, 515-525. http://dx.doi.org/10.1093/clinids/14.2.515

[27] Besancenot, J.P., Boko, M. and Oke, P.C. (1997) Weather Conditions and Cerebrospinal Meningitis in Benin (Gulf of Guinea, West Africa). European Journal of Epidemiology, 13, 807-815. http://dx.doi.org/10.1023/A:1007365919013

[28] Savory, E.C., Cuevas, L.E., Yassin, M.A., Hart, C.A., Molesworth, A.M. and Thomson, M.C. (2006) Evaluation of the Meningitis Epidemics Risk Model in Africa. Epidemiology and Infection, 134, 1047-1051. http://dx.doi.org/10.1017/S0950268806005929

[29] MERIT (2012) Meningits Environmental Risk Information. 6th International MERIT Techinical Meeting, Accara, 2728 November 2012.

[30] Abdussalam, A.F., et al. (2014) The Impact of Climate Change on Meningitis in Northwest Nigeria: An Assessment Using CMIP5 Climate Model Simulations. Weather, Climate, and Society, 6, 371-379. http://dx.doi.org/10.1175/WCAS-D-13-00068.1

[31] Soro, B.N., et al. (1988) Epidemiological Aspects of Meningitis in the North of the Ivory Coast. Medecine Tropicale: Revue du Corps de sante colonial, 48, 145-148.

[32] Leckebusch, G.C. and Abdussalam, A.F. (2015) Climate and Socioeconomic Influences on Interannual Variability of Cholera in Nigeria. Health \& Place, 34, 107-117. http://dx.doi.org/10.1016/j.healthplace.2015.04.006 


\section{Submit or recommend next manuscript to SCIRP and we will provide best service for you:}

Accepting pre-submission inquiries through Email, Facebook, LinkedIn, Twitter, etc.

A wide selection of journals (inclusive of 9 subjects, more than 200 journals)

Providing 24-hour high-quality service

User-friendly online submission system

Fair and swift peer-review system

Efficient typesetting and proofreading procedure

Display of the result of downloads and visits, as well as the number of cited articles

Maximum dissemination of your research work

Submit your manuscript at: http://papersubmission.scirp.org/ 